\title{
Short communication: The effects of frozen storage on the survival of probiotic microorganisms found in traditionally and commercially manufactured kefir
}

\author{
K. V. O'Brien, ${ }^{* 1}$ K. J. Aryana, ${ }^{*}$ W. Prinyawiwatkul, $†$ K. M. Carabante Ordonez, $†$ and C. A. Boeneke* \\ ${ }^{*}$ School of Animal Sciences, Louisiana Agricultural Experiment Station, Louisiana State University Agricultural Center, Baton Rouge 70803 \\ †School of Nutrition and Food Sciences, Louisiana State University, Baton Rouge 70803
}

\begin{abstract}
Kefir is a fermented milk traditionally made from a unique starter culture, which consists of numerous bacteria and yeast species bound together in an exopolysaccharide matrix produced by certain lactic acid bacteria. Many health benefits are associated with traditionally produced kefir; however, bulging and leaking packaging, caused by secondary yeast fermentation during storage, has limited large-scale manufacture. Commercial kefir products have been designed to reduce these effects by using a pure starter culture consisting of a mixture of bacteria and yeast species that give a flavor similar to traditional kefir, but some health benefits may be lost in commercial production due to reduced microbial diversity and lack of beneficial exopolysaccharides. In this study, traditional and commercial kefir was frozen to study the effects of frozen storage on the viability of probiotic bacteria over time. Traditional kefir was prepared by inoculating $1 \mathrm{~L}$ of pasteurized whole goat milk with approximately $30 \mathrm{~g}$ of kefir grains. Commercial kefir was prepared by inoculating $1 \mathrm{~L}$ of full-fat, pasteurized goat milk with a commercial kefir starter. The milk was allowed to ferment at room temperature $\left(24-28^{\circ} \mathrm{C}\right)$ until $\mathrm{pH} 4.6$ was reached. Samples were frozen $\left(-8\right.$ to $\left.-14^{\circ} \mathrm{C}\right)$ immediately following the completion of fermentation and were thawed and plated for lactobacilli, lactococci, and yeasts on d 0, 7, 14, and 30 of frozen storage. Lactobacilli, lactococci, and yeasts were significantly reduced in number during frozen storage; however, the traditionally produced kefir was shown to have significantly higher counts of bacteria and yeast at each sampling. We concluded that frozen storage and the development of frozen kefir products could eliminate most packaging concerns associated with the large-scale manufacture of traditionally produced kefir,
\end{abstract}

Received August 19, 2015.

Accepted April 30, 2016.

${ }^{1}$ Corresponding author: kobrie9@lsu.edu resulting in increased production and marketability of this healthful product.

Key words: kefir, kefir grains, probiotics, frozen dairy

\section{Short Communication}

In order for a probiotic to benefit human health it must have good technological properties, survive through the upper gastrointestinal tract, and be able to function in the gut environment (Mattila-Sandholm et al., 2002). These properties, as well as many health benefits, have been examined, and kefir has demonstrated a wide array of positive effects such as antitumor and immunostimulating activity in animals (Quiros et al., 2005). With kefir, both prebiotic and probiotic benefits are incurred by the consumer, including competitive exclusion of pathogenic bacteria, increased absorption of nutrients, and immunomodulating effects such as the modification of the balance of immune cells in the intestinal mucosa (Vinderola et al., 2006; Medrano et al., 2008; Maalouf et al., 2011).

During kefir manufacture with grains, lactic acid fermentation slows considerably or stops as the $\mathrm{pH}$ declines, but the yeast fermentations continue, allowing for an increase in ethanol production during storage. The secondary alcohol fermentations can lead to substantial changes in flavor as well as bulging or leaking packaging due to the continued production of carbon dioxide gas (Kwak et al., 1996). Commercial kefir production uses a dry starter culture usually containing of up to 12 species isolated from lyophilized kefir grains.

The development of commercial starter cultures has allowed for widespread distribution of kefir and kefir products; however, the demand for traditionally produced kefir is rising, and methods for producing a consistent product with an adequate shelf life are still being developed. This indicates that the consumer preference might be for a product with a flavor akin to traditionally produced kefir. Because taste preferences are met by traditionally produced kefir and because of possible added health benefits of traditional over com- 
mercial kefir, frozen storage and transport could serve as an alternative solution to the problems typically associated with traditionally produced kefir.

Microorganisms present in a cultured dairy product have a high survivability rate; however, numerous reports have observed structural damage to living lactobacilli cells when subjected to freezing and thawing (Breunan et al., 1986; Lopez et al., 1998). Therefore, other considerations, such as the freezing method, must also be taken into account when attempting to provide a product with the highest number of surviving probiotics.

Exopolysaccharides, such as kefiran, might also serve to enhance the survival of probiotic organisms in a frozen dessert by providing a protective coat that may help to ameliorate the harsh conditions associated with freezing and thawing. A study by Monnet et al. (2003) showed a significantly higher cryotolerance during freezing of Lactobacillus delbrueckii strains with a mutation causing an excess production of exopolysaccharide.

Consumer acceptability of acidified dairy foods is typically high in sensory tests conducted on other frozen dairy desserts, such as frozen yogurt (Guinard et al., 1994). The same study also showed that the most-preferred samples of frozen yogurt were the ones with the lowest acidity; these results suggest that an ideal frozen dairy dessert, for most consumers, should combine the sensory properties of ice cream and the nutritional benefits of yogurt (Guinard et al., 1994). However, flavored traditional kefir, which scored high during sensory studies, might be more acceptable to the Western palate than unflavored kefir (Muir et al., 1999). The objective of this study was to quantify viable probiotic bacteria and yeasts in traditionally and commercially produced kefir following various periods of frozen storage.

Two types of kefir were made: one was traditionally produced by inoculation of milk with kefir grains, and the second was made by inoculating milk with a commercial kefir starter. Once fermented, the kefir was divided into 4 aliquots. Three were frozen immediately, and the fourth was left unfrozen and served as a control. The samples were then tested for 3 different types of probiotics: lactobacilli, lactococci, and yeasts. The entire experiment was repeated in triplicate.

Traditional kefir was be prepared by inoculating 1 L of full-fat, pasteurized goat milk (Ryals Goat Dairy, Tylertown, MS) with kefir grains in a liter-sized glass jar. Thirty grams of kefir grains (Cultures for Health, Morrisville, NC) were added to $1 \mathrm{~L}$ of milk to give a 3 to $5 \%$ ratio of kefir grains to milk as described by Chen et al. (2005). The grains were cultivated, using this method and with the addition of fresh milk weekly, in the Louisiana State University Creamery Building for several months before experimental use.

Commercial kefir was prepared by inoculating $1 \mathrm{~L}$ of full-fat, pasteurized goat milk with a commercial kefir starter (Lyo-San, Inc., Lachute, QC, Canada) in a liter-sized glass jar. The milk was allowed to ferment at room temperature $\left(24-28^{\circ} \mathrm{C}\right)$ and was agitated by manually shaking every few hours for approximately $24 \mathrm{~h}$ to ensure proper mixing of the grains and milk. The kefir fermentation was considered complete when a $\mathrm{pH}$ of 4.6 was reached. The grains used to ferment the traditional kefir were recovered by straining the kefir through a fine mesh sieve.

Three 50-g samples of both the traditional and commercial kefirs were collected in separate food-grade plastic containers before storage at $-14 \pm 6^{\circ} \mathrm{C}$, the temperature range that encompasses most household freezers. The samples were frozen immediately following the completion of fermentation (approximately 24 h). The samples were thawed and plated on d 7, 14, and 30 of frozen storage. One additional sample was not frozen and was used as the control for each replication of the experiment; this sample was plated for probiotic microorganisms immediately following fermentation. The frozen samples were allowed to thaw at room temperature for $4 \mathrm{~h}$ and were incubated at $37^{\circ} \mathrm{C}$ for $1 \mathrm{~h}$ before plating (Hong and Marshall, 2001).

To quantify the amounts of probiotic bacteria and yeasts in each sample, serial dilutions were made using $0.1 \%$ peptone water (Becton, Dickinson and Company, Sparks, MD; Mian et al., 1997). The peptone water was sterilized by autoclaving at $121^{\circ} \mathrm{C}$ for $15 \mathrm{~min}$, then cooled to approximately $27^{\circ} \mathrm{C}$ and inoculated with $1 \%$ ( vol/vol) kefir and further diluted to $10^{-10}$. The kefir samples were plated for lactobacilli and lactococci using de Man, Rogosa, and Sharpe (MRS) agar (Merck, Darmstadt, Germany) and M17 (Becton, Dickinson and Company) agars (Witthuhn et al., 2005a; Garcia Fontan et al., 2006). To prevent the growth of yeasts on the bacterial plates, $200 \mathrm{mg} / \mathrm{L}$ of cycloheximide (Acros, Geel, Belgium) was added to the MRS and M17 agars (Chen et al., 2008). Several dilutions of each sample were plated and each dilution was plated in triplicate. The MRS and M17 plates were incubated anaerobically for 72 and $48 \mathrm{~h}$ at $32^{\circ} \mathrm{C}$ (Irigoyen et al., 2005). Yeasts were grown on yeast extract glucose chloramphenicol agar (Merck) for $5 \mathrm{~d}$ at $25^{\circ} \mathrm{C}$ under aerobic conditions (Gronnevik et al., 2011). Following incubation, growth was determined by counting the number of bacterial and yeast colonies on each plate; colony totals were presented as colony-forming units per milliliter of kefir.

Statistical analysis was performed using the repeated measures ANOVA F-test, with a confidence interval of 
Table 1. The effects of type and storage treatments on the reduction of microorganisms

\begin{tabular}{lccr}
\hline & \multicolumn{3}{c}{$P>\mathrm{F}$} \\
\cline { 2 - 4 } Effect $^{1}$ & Lactobacilli & Lactococci & Yeasts \\
\hline Type & $<0.0001$ & 0.0094 & $<0.0001$ \\
Storage & $<0.0001$ & $<0.0001$ & $<0.0001$ \\
Type $\times$ storage & $<0.0001$ & $<0.0001$ & 0.2137 \\
\hline
\end{tabular}

${ }^{1}$ Type $=$ traditional and commercial kefir; storage $=30 \mathrm{~d}$.

95\% $(P<0.05)$. Analysis of covariance (ANCOVA) was used to determine the rate of microbial reduction as represented by the slope of the regression. Statistical analysis was performed using the SAS Software Package version 9.3 (SAS Institute Inc., Cary, NC).

The overall reduction for lactobacilli in the traditional and commercial kefir was found to be significantly $(P<0.05)$ different (Table 1$)$. The lactobacilli populations found in the traditional kefir also decreased at a slower rate than the lactobacilli populations in the commercial kefir during frozen storage (Table 2). The overall reduction of lactococci in the traditional kefir was not significantly $(P>0.05)$ different than in the commercial kefir (Figure 1) before freezing; however, the reduction rates of the lactococci in the traditional and commercial kefirs were significantly $(P<0.05)$ different between each time interval during the $30 \mathrm{~d}$ of frozen storage (Table 3). The reduction rate of yeasts found in the traditional kefir was not found to be significantly $(P>0.05)$ different than the reduction rate of yeasts in commercial kefir (Table 1).

Once the interactions between the effects of storage period and the type of kefir were determined, the individual rates of microbial reduction all 3 probiotic types between the traditional and commercial kefir were compared. Figure 1 presents rates of microbial reduction (slope) during the frozen storage period.

When subjected to frozen storage conditions, the lactobacilli in the traditionally prepared kefir showed a significant decrease in number after storage for 30

Table 2. Mean counts (log cfu/mL) of viable lactobacilli following storage for up to $30 \mathrm{~d}$

\begin{tabular}{lcccc}
\hline & \multicolumn{4}{c}{ Lactobacilli } \\
\cline { 2 - 5 } $\begin{array}{l}\text { Treatment } \\
\text { kefir type) }\end{array}$ & Control & d 7 & d 14 & d 30 \\
\hline Traditional & $10.41^{\mathrm{A}, \mathrm{a}}$ & $8.48^{\mathrm{B}, \mathrm{a}}$ & $8.00^{\mathrm{C}, \mathrm{a}}$ & $7.24^{\mathrm{D}, \mathrm{a}}$ \\
Commercial & $9.15^{\mathrm{A}, \mathrm{b}}$ & $8.95^{\mathrm{B}, \mathrm{b}}$ & $6.61^{\mathrm{C}, \mathrm{b}}$ & $6.33^{\mathrm{D}, \mathrm{b}}$ \\
\hline
\end{tabular}

$\overline{\mathrm{A}-\mathrm{D}}$ Values with the same uppercase letter within the row are not significantly different $(P<0.05)$.

${ }^{\mathrm{a}, \mathrm{b}}$ Values with the same letter within the column are not significantly different $(P<0.05)$.
Table 3. Mean counts (log $\mathrm{cfu} / \mathrm{mL}$ ) of viable lactococci following storage for up to $30 \mathrm{~d}$

\begin{tabular}{|c|c|c|c|c|}
\hline \multirow{2}{*}{$\begin{array}{l}\text { Treatment } \\
\text { (kefir type) }\end{array}$} & \multicolumn{4}{|c|}{ Lactococci } \\
\hline & Control & d 7 & d 14 & d 30 \\
\hline Traditional & $9.32^{\mathrm{A}, \mathrm{a}}$ & $8.87^{\mathrm{B}, \mathrm{a}}$ & $7.36^{\mathrm{C}, \mathrm{a}}$ & $6.24^{\mathrm{D}, \mathrm{a}}$ \\
\hline Commercial & $9.00^{\mathrm{A}, \mathrm{b}}$ & $8.71^{\mathrm{B}, \mathrm{b}}$ & $6.55^{\mathrm{C}, \mathrm{b}}$ & $5.44^{\mathrm{D}, \mathrm{b}}$ \\
\hline
\end{tabular}

$\mathrm{d}$, and significant $(P<0.05)$ differences were found between bacterial counts in the traditional kefir at all time intervals tested (Table 2; Figure 2). The lactobacilli in the commercial kefir was also significantly $(P$ $<0.05)$ different at the end of the storage period and significant differences were found at all time intervals.

Guzel-Seydim et al. (2005) found $10^{9}$ counts of lactic acid bacteria in Turkish kefir, with lactobacilli species predominating. However, previous studies on Irish kefir grains, performed by Rea et al. (1996), showed that the grains as well as the fermented milk contained (cfu/ $\mathrm{mL}) 10^{6}$ lactobacilli. The findings presented in the current study show the amount of lactobacilli present in the commercial kefir is consistent with several previous studies (Garcia Fontan et al., 2006; De Oliveira Leite et al., 2013); those studies also found the counts of presumptive lactobacilli obtained from kefir produced with grains were on the order of one log higher than lactobacilli from kefir produced with a commercial starter. Witthuhn et al. (2005b) reported varying lactobacilli numbers during kefir production between $4.6 \times 10^{3}$ and $2.6 \times 10^{8}$. These numbers reflect kefir produced commercially and traditionally, with the traditional kefir consistently representing the larger values, meaning that traditional kefir was consistently found to have a higher overall microbial load when compared with commercial kefir.

When subjected to frozen storage conditions, the lactococci in the traditionally prepared kefir showed a significant $(P<0.05)$ decrease in number after storage for $30 \mathrm{~d}$, and significant $(P<0.05)$ differences were found between all time intervals tested (Table 3; Figure $3)$. Significant $(P<0.05)$ differences in both the overall reduction at the end of the 30-d storage period and the reduction between each storage interval were also observed in the commercial kefir $(P<0.05)$.

Results presented by Rea et al. (1996) showed the contents of Irish kefir grains to be (cfu/mL) $10^{9}$ lactococci. This is consistent with the numbers of lactococci observed in our study but the counts reported here $\left(10^{9}\right.$ $\mathrm{cfu} / \mathrm{g})$ were 2 logs lower than in studies by Beshkova et al. (2002), who reported cells counts of $10^{11} \mathrm{cfu} / \mathrm{g}$ 


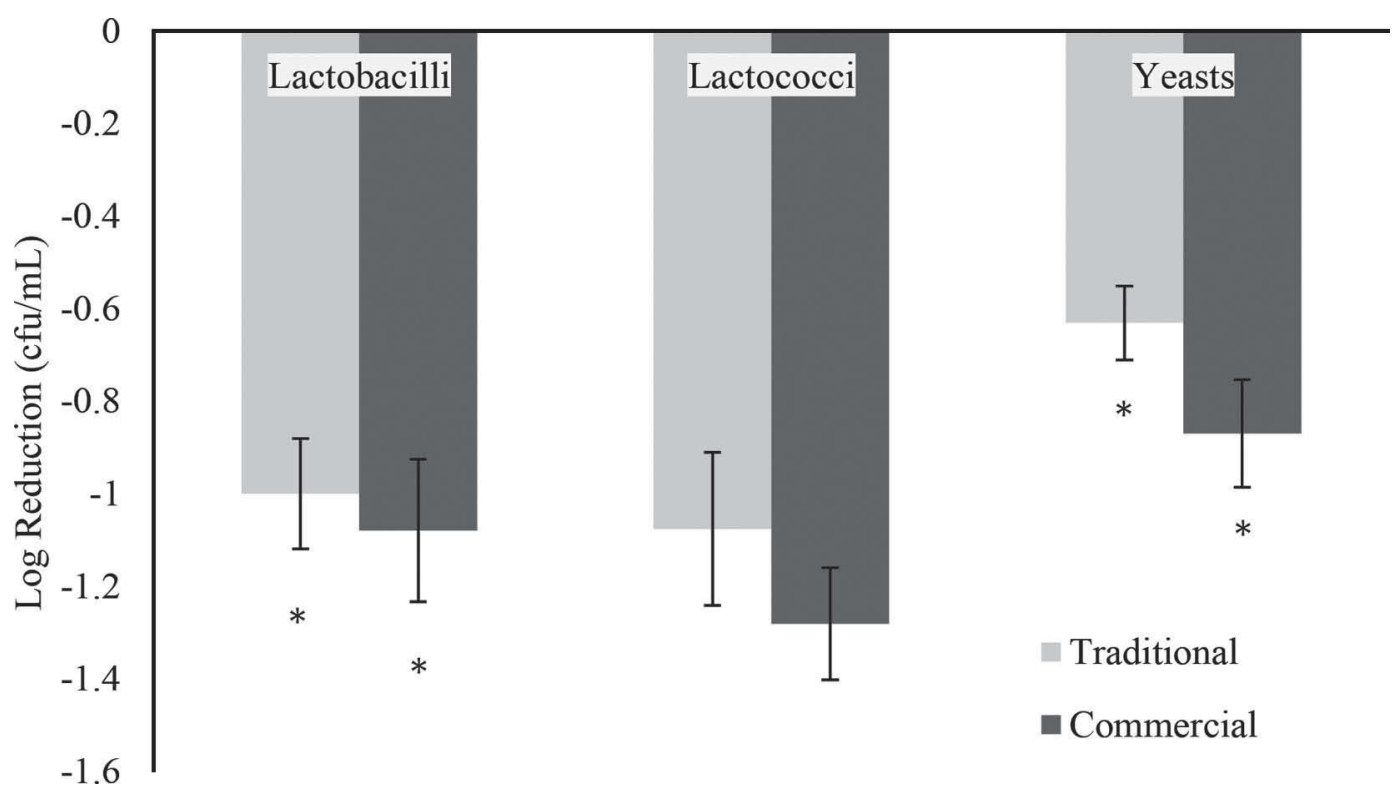

Figure 1. Reduction of lactobacilli, lactococci, and yeast populations in traditional and commercial kefir during $30 \mathrm{~d}$ of frozen storage. An asterisk $(*)$ indicates $\log$ reduction values for each microbial category that are significantly $(P<0.05)$ different between kefir types. Values are reported as mean $\pm \mathrm{SD}$.

for both traditional and commercial kefir immediately following fermentation. In Guzel-Seydim et al. (2005), a microbial enumeration and electron microscopy were performed on Turkish kefir and kefir grains and found no lactococci present in any portion of the kefir grain; however, lactococci were enumerated to $10^{8}$ in the traditional kefir beverage. The absence of lactococci in the kefir grain, and its subsequent growth in fermenting kefir, may have been caused by the unintentional

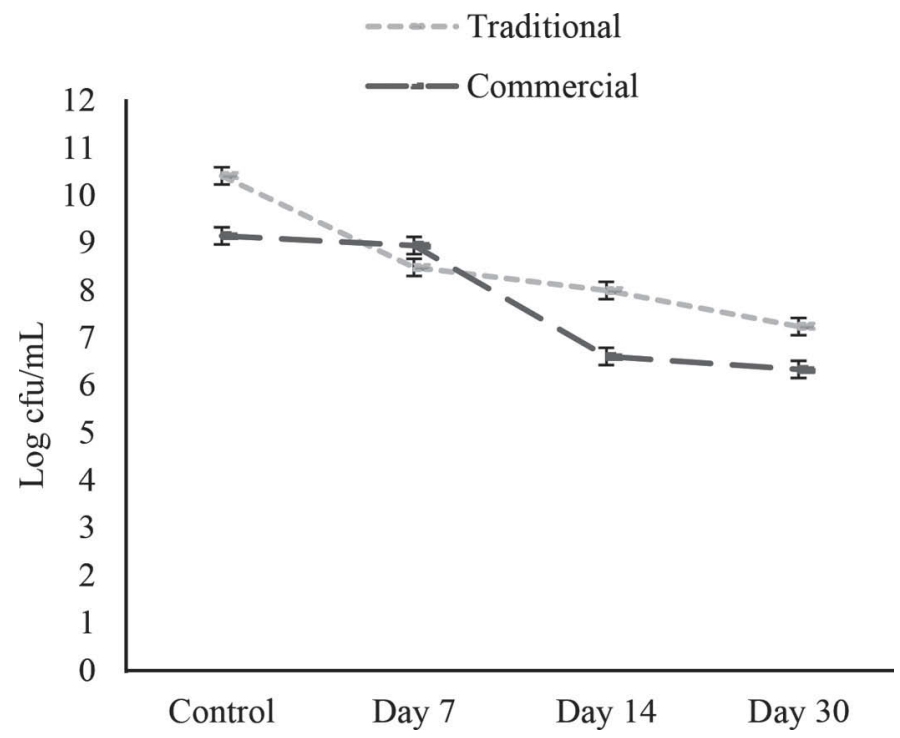

Figure 2. Reduction of lactobacilli in traditional and commercial kefir during $30 \mathrm{~d}$ of frozen storage. Values are reported as mean $\pm \mathrm{SD}$. removal of lactococci from the surface of the grains during manufacture into the milk medium where it is able to proliferate; this would most likely occur due to agitation during the manufacturing process (GuzelSeydim et al., 2005). Because the lactococci present in kefir are not known to produce any exopolysaccharides that may help with adhesion to the grain, they may not be able to attach and become incorporated into the kefir grain.

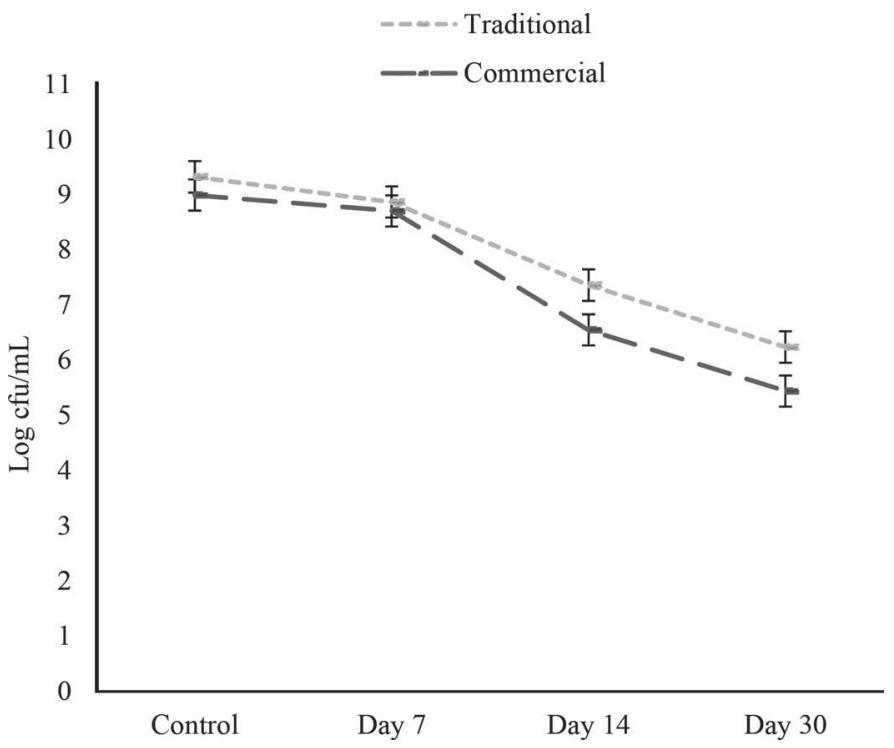

Figure 3. Reduction of lactococci in traditional and commercial kefir during $30 \mathrm{~d}$ of frozen storage. Values are reported as mean $\pm \mathrm{SD}$. 
Table 4. Mean counts $(\log \mathrm{cfu} / \mathrm{mL})$ of viable yeasts following storage for up to $30 \mathrm{~d}$

\begin{tabular}{lcccc}
\hline & \multicolumn{4}{c}{ Yeasts } \\
\cline { 2 - 5 } $\begin{array}{l}\text { Treatment } \\
\text { (kefir type) }\end{array}$ & Control & $\mathrm{d} 7$ & $\mathrm{~d} 14$ & $\mathrm{~d} 30$ \\
\hline Traditional & $8.83^{\mathrm{A}, \mathrm{a}}$ & $8.40^{\mathrm{B}, \mathrm{a}}$ & $8.13^{\mathrm{C}, \mathrm{a}}$ & $6.82^{\mathrm{D}, \mathrm{a}}$ \\
Commercial & $7.20^{\mathrm{A}, \mathrm{b}}$ & $5.56^{\mathrm{B}, \mathrm{b}}$ & $5.32^{\mathrm{C}, \mathrm{b}}$ & $4.38^{\mathrm{D}, \mathrm{b}}$ \\
\hline
\end{tabular}

$\overline{\mathrm{A}-\mathrm{D}}$ Values with the same letter within the row are not significantly different $(P<0.05)$.

${ }^{\mathrm{a}, \mathrm{b}}$ Values with the same letter within the column are not significantly different $(P<0.05)$

The decrease of lactococci bacteria in the traditional kefir was significantly $(P>0.05)$ different from the decrease of lactococci in the commercial kefir. The traditional kefir ultimately contained more lactococci at the end of the $30 \mathrm{~d}$ of frozen storage, as seen by significantly $(P<0.05)$ less lactococci in the commercial kefir than the in the traditional kefir.

When subjected to frozen storage conditions, the yeasts in the traditionally prepared kefir showed a significant $(P<0.05)$ decrease in number after storage for $30 \mathrm{~d}$, and significant $(P<0.05)$ differences in yeast numbers for traditional kefir were found between all time intervals tested (Table 4; Figure 4). No significant $(P>0.05)$ differences in reduction rate of yeasts were observed between the traditional and commercial kefir. The commercial kefir was also shown to have significant $(P<0.05)$ reductions in viable yeasts between intervals and following the full $30 \mathrm{~d}$ of frozen storage.

The population of yeasts was lower than the lactic acid populations in both the traditional and commercial kefir. The initial counts of $10^{8} \mathrm{cfu} / \mathrm{g}$ in traditional kefir observed were higher than the $10^{7} \mathrm{cfu} / \mathrm{g}$ found by Wang et al. (2008); however, these results were lower than previous yeast counts in traditional kefir of $10^{5}$ $\mathrm{cfu} / \mathrm{g}$, as reported by Beshkova et al. (2002). Fermentation conditions, most likely a fluctuating decrease in ambient temperature, could have resulted in a more favorable environment for the yeasts and caused the high numbers in our study. However, the commercial kefir is consistent with findings by Beshkova et al. (2002), who reported the total number of yeasts to be $10^{6}$ to $10^{7} \mathrm{cfu} / \mathrm{g}$ in kefir made with pure cultures. During storage under refrigeration, the yeast populations showed marked growth in traditional kefir due to their increased consumption of bacterial metabolites (Guzel-Seydim et al., 2000). The quantity of yeasts in our study correlate more directly with the yeast counts observed directly after fermentation; therefore, it would be expected that the amount of yeasts in frozen kefir would be lower than an unfrozen, stored kefir.

The effects of freezing kefir that has been formulated into a mix, containing sugar and other flavorings, as well as freezing method must also be examined to more accurately predict the probiotic counts that will be present in the finished product and available to the consumer. The added agitation and scraping of freezer barrel walls needed to achieve proper overrun in frozen dairy desserts may lower the rate of survival, and cellular exposure to oxygen during whipping might also increase cell death due to exposure to free radicals (Marshall, 2001). These variables must be considered when determining the full protective potential of naturally occurring exopolysaccharides on the probiotics.

However, the constantly shifting ecology that is unique to traditionally manufactured kefir may further enhance the total number of viable bacteria by ensuring, with a very wide range of species, that a high percentage of diverse populations will survive conditions such as freezing, thawing, and exposure to acids and bile salts required for digestion. The exopolysaccharide, kefiran, produced by a strain specific to traditionally manufactured kefir, has been shown to aid in the colonization of the gut, with beneficial bacteria and yeasts by providing adhesion of probiotic species to the epithelium. For these reasons, the consumption of traditionally produced kefir might be preferred over kefir produced from isolated starter cultures as a way to ensure greater survival and wider range of probiotic species. A frozen product made from traditional kefir would provide a microbial load great enough to be considered a beneficial supplement to the consumer, and the distribution problems typically associated with refrigerated transport and storage would be eliminated.

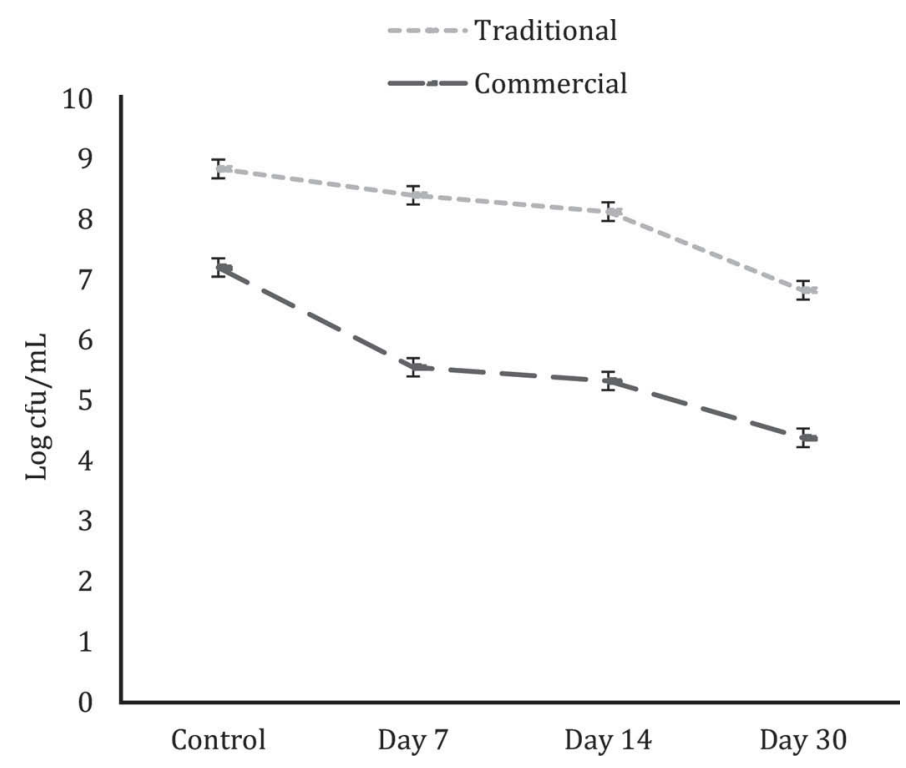

Figure 4. Reduction of yeasts in traditional and commercial kefir during $30 \mathrm{~d}$ of frozen storage. Values are reported as mean $\pm \mathrm{SD}$. 


\section{ACKNOWLEDGMENTS}

The study was funded by Louisiana State University Agricultural Center, Baton Rouge.

\section{REFERENCES}

Beshkova, D. M., E. D. Simova, Z. I. Simova, G. I. Frengova, and Z. N. Spasov. 2002. Pure cultures for making kefir. Food Microbiol. 19:537-544.

Breunan, M., B. Warusinail, M. C. Johnson, and B. Ray. 1986. Cellular damage in dried Lactobacillus acidophilus. J. Food Prot. 49:47-53.

Chen, H. C., S. Y. Wang, and M. J. Chen. 2008. Microbiological study of lactic acid bacteria in kefir grains by culture-dependent and culture-independent methods. Food Microbiol. 25:492-501.

Chen, M. J., J. R. Liu, C. W. Lin, and Y. T. Yeh. 2005. Study of the microbial and chemical properties of goat milk kefir produced by inoculation with Taiwanese Kefir grains. Asian-Australas. J. Anim. Sci. 18:711-715.

de Oliveira Leite, A. M., M. A. L. Miguel, R. S. Peixoto, A. S. Rosado, J. T. Silva, and V. M. F. Paschoalin. 2013. Microbiological, technological and therapeutic properties of kefir: A natural probiotic beverage. Braz. J. Microbiol. 44:341-349.

Garcia Fontan, M. C., S. Martinez, F. Franco, and J. Carballo. 2006. Microbiological and chemical changes during the manufacture of Kefir made from cows' milk, using a commercial starter culture. Int. Dairy J. 16:762-767.

Gronnevik, H., M. Falstad, and J. A. Narvhus. 2011. Microbiological and chemical properties of Norwegian kefir during storage. Int. Dairy J. 21:601-606.

Guinard, J. X., C. Little, C. Marty, and T. Palchak. 1994. Effect of sugar and acid on the acceptability of frozen yogurt to student population. J. Dairy Sci. 77:1232-1238.

Guzel-Seydim, Z., A. C. Seydim, and A. K. Greene. 2000. Organic acids and volatile flavor components evolved during refrigerated storage of kefir. J. Dairy Sci. 83:275-277.

Guzel-Seydim, Z., J. T. Wyffels, A. C. Seydim, and A. K. Greene. 2005. Turkish kefir grains: Microbial enumeration and electron microscopic observation. Int. J. Dairy Technol. 58:25-29.

Hong, S. H., and R. T. Marshall. 2001. Natural exopolysaccharides enhance survival of lactic acid bacteria in frozen dairy desserts. J. Dairy Sci. 84:1367-1374

Irigoyen, A., I. Arana, M. Castiella, P. Torre, and F. C. Ibanez. 2005. Microbiological, physicochemical, and sensory characteristics of kefir during storage. Food Chem. 90:613-620.
Kwak, H. S., S. K. Park, and D. S. Kim. 1996. Biostabilization of kefir with a non-lactose fermenting yeast. J. Dairy Sci. 79:937-942.

Lopez, M. C., L. M. Medina, and R. Jordano. 1998. Survival of lactic acid bacteria in commercial frozen yogurt. J. Food Sci. 63:706-708.

Maalouf, K., E. Baydoun, and S. Rizk. 2011. Kefir induces cell-cycle arrest and apoptosis in HTVL-I-negative malignant T-lymphocytes. Cancer Manag. Res. 3:39-47.

Marshall, R. T. 2001. Frozen desserts. Page 109 in Applied Dairy Microbiology. 2nd ed. Marcel Dekker, New York, NY.

Mattila-Sandholm, T., P. Myllarinen, R. Crittenden, G. Mogensen, R. Fonden, and M. Saarela. 2002. Technological challenges for future probiotic foods. Int. Dairy J. 8:173-182.

Mian, M. A., G. H. Fleet, and A. D. Hocking. 1997. Effect of diluent type on viability of yeasts enumerated form foods or pure cultures. Int. J. Food Microbiol. 35:103-107.

Monnet, C., C. Beal, and G. Corrieu. 2003. Improvement of the resistance of Lactobacillus delbrueckii ssp. bulgaricus to freezing by natural selection. J. Dairy Sci. 86:3048-3053.

Muir, D. D., A. Y. Tamime, and M. Wszolek. 1999. Comparison of the sensory profiles of kefir, buttermilk and yogurt. Int. J. Dairy Technol. 52:129-135.

Quiros, A., B. Hernandez, M. Ramos, L. Amigo, and I. Recio. 2005. Angiotensin-converting enzyme inhibitory activity of peptides derived from caprine kefir. J. Dairy Sci. 88:3480-3487.

Rea, M. C., T. Lennartsson, P. Dillon, F. D. Drinan, W. J. Reville, M. Heapes, and T. M. Cogan. 1996. Irish kefir-like grains: Their structure, microbial composition and fermentation kinetics. J. Appl. Bacteriol. 81:83-94.

Vinderola, G., G. Perdigon, J. Duarte, E. Farnsworth, and C. Matar. 2006. Effects of oral administration of the exopolysaccharide produced by Lactobacillus kefiranofaciens on the gut mucosal immunity. Cytokine 36:254-260.

Wang, S. Y., H. C. Chen, J. R. Liu, Y. C. Lin, and M. J. Chen. 2008. Identification of yeasts and evaluation of their distribution in Taiwanese kefir and villi starters. J. Dairy Sci. 91:3798-3805.

Witthuhn, R. C., T. Schoeman, and T. J. Britz. 2005a. Characterization of the microbial population at different stages of kefir production and kefir grain mass cultivation. Int. Dairy J. 15:383-389.

Witthuhn, R. C., T. Schoeman, A. Cilliers, and T. J. Britz. 2005b. Impact of preservation and different packing conditions on the microbial community and activity of kefir grains. Food Microbiol. $22: 337-344$. 